\title{
A Brief Follow-Up Report on 228 Medial Rotation Total Knee Replacements at a Mean of 8.5 Years $(0$ - 19)
}

\author{
Sarah McMahon, Gareth Scott \\ Bone and Joint Research Unit, Royal London Hospital, London, UK \\ Email: drsarahmcmahon@gmail.com
}

Received 4 November 2015; accepted 22 December 2015; published 25 December 2015

Copyright (C) 2015 by authors and Scientific Research Publishing Inc.

This work is licensed under the Creative Commons Attribution International License (CC BY). http://creativecommons.org/licenses/by/4.0/

c) (i) Open Access

\begin{abstract}
We present an update in our earlier report on the Medial Rotation Total Knee Arthroplasty (TKA) when a cohort of 228 TKAs in 189 patients $(78 \mathrm{M} ; 111 \mathrm{~F})$ with a mean age of 67.9 years $(28-90)$ was reported at a mean follow-up of six years $(1-13)$. At that time, the ten-year survivorship for revision for any reason was $94.5 \%$ (95\% confidence interval (CI): $85.1-100)$, but only 21 knees were at risk at that tenth year. The 10th annual report of the National Joint Registry (NJR) of England, Wales and Northern Ireland reported a deterioration in survivorship of the Medial Rotation TKA beyond the seventh year of follow-up. This implant previously had enjoyed the lowest rate of revision for any reported brand of prosthesis. As a result, we undertook a comprehensive audit of our original cohort at a mean follow-up of 8.5 years $(0$ - 19). With revision for aseptic loosening, and revision for any reason as the endpoints, with 125 prostheses at risk at ten years, the ten-year survivorship was $96.7 \%$ (95\% CI: 93.3 - 100) and 92.3\% (95\% CI: 87.7 - 93.7) respectively. We have confirmed a decline in survivorship at ten years compared to our initial report. We believe that our results probably provide a more accurate picture of the longevity of the implant than figures available from the NJR, as they are based on detailed contemporary enquiries into each patient's circumstances. Only ten knees in seven patients were lost to follow-up in our review.
\end{abstract}

\section{Keywords}

Knee, Arthroplasty, Revision, Aseptic Loosening, Survivorship, National Joint Registry

\section{Introduction}

In 2009, we reported the clinical and radiological outcome of the Medial Rotation Total Knee Arthroplasty

How to cite this paper: McMahon, S. and Scott, G. (2015) A Brief Follow-Up Report on 228 Medial Rotation Total Knee Replacements at a Mean of 8.5 Years (0 - 19). International Journal of Clinical Medicine, 6, 928-933. 
(TKA) (formerly Finsbury Orthopaedics, now MatOrtho, Leatherhead, United Kingdom) in 228 consecutive primary cemented TKAs undertaken in 189 patients who underwent operation between October 1994 and October 2006 [1]. At a mean follow-up of six years (1 to 13), the ten year survivorship for revision for any reason was $94.5 \%$ (95\% confidence intervals (CI): 85.1 - 100) and with aseptic loosening as the endpoint $98.4 \%$ (95\% CI: 93 - 100). However, only 21 knees remained at risk at that time.

The Medial Rotation TKA was developed from the Freeman-Samuelson Prosthesis (Zimmer Centerpulse, Baar, Switzerland). The radius of curvature of the medial femoral condyle was increased, and it was shaped as a portion of a sphere. The polyethylene medially was given a matching concavity, and the increased congruency was intended to reduce the contact stresses on the polyethylene, to confer greater stability, and to allow some rotation around the medial sphere. The evolution of the design concept had been described previously [1].

In the 9th Annual Report (2012) of the National Joint Registry (NJR) for England and Wales, of the brands with specified outcomes, the Medial Rotation TKA had the lowest revision rate of 1.33\% (95\% CI: 0.88 - 2.02) at seven years follow-up with 4712 prostheses recorded [2]. This represented only a small proportion of the 414,768 fully cemented TKAs registered with the NJR from 2003 to 2011. The 10th Annual Report (2013) of the expanded NJR for England, Wales and Northern Ireland, still identified the Medial Rotation TKA with the lowest revision rate at seven years of 1.83\% (95\% CI: 1.42 - 2.36) but at nine years, the revision rate had deteriorated to 3.33\% (95\% CI: 1.74 to 6.31) [3]. We therefore felt that it was appropriate to update our previous report, given that so few prostheses in our original series were at risk at ten years.

\section{Patients and Methods}

We undertook a comprehensive survey of all the patients previously reported to establish the current survivorship of the arthroplasty. Regional Ethics Committee approval was not required as this review fell within the remit of service evaluation. We verified the accuracy of our database by searching the hospital's electronic medical records to determine the number of patients who had died in the period since our last report, and if the cause of death was related to their TKA. In addition we identified whether any patients had undergone revision surgery, and if so why. When information was not immediately available we contacted the patients by telephone, or spoke to their next of kin, their new consultant if their care was now being provided elsewhere, and when necessary their last recorded general practitioner, to establish as comprehensively possible, the patients' current circumstances. In this manner we also established whether any patients were pending revision or had retained their implants despite being in need of revision due to a reluctance to undergo further surgery, or because a comorbidity precluded further intervention. This audit, in July 2014, did not involve clinical examination or obtaining new radiographs but when our enquiries stimulated renewed interest, patients were accepted for review when sanctioned by their general practitioner.

The patients have been described in full previously but in brief, 78 men (17 with bilateral) and 111 women (22 bilateral) underwent TKA for osteoarthritis in 174 knees, rheumatoid arthritis in 39 knees and for posttraumatic arthritis or other causes in 15; the mean age at the time of surgery was 67.9 years (28 to 90) [1].

The fully cemented Medial Rotation TKA was introduced into clinical practice in 1994. It was the first unconstrained prosthesis to feature a medial condylar design, which was represented by a portion of a sphere (25 $\mathrm{mm}$ radius) and matched a congruent concaved polyethylene insert. These features were intended to provide stability to the TKA throughout the whole range of flexion [4]. The lateral condylar design was a single $24 \mathrm{~mm}$ anteroposterior radius design, with a matching concavity in the lateral side of the polyethylene insert intended to tolerate some rotation around the medial sphere and thereby conform to the reported kinematics of the natural knee [5]-[8].

\section{Statistical Analysis}

The outcome of this update is presented as a survival analysis using the life-table method [9] [10], with the 95\% CI calculated using the same bespoke software used in our first report [1], with three endpoints applied. Firstly, aseptic loosening was analysed as an endpoint, with any revision for another reason treated as a death for this calculation. Secondly, the scenario of revision for any reason, pending revision or a failed implant retained but unrevised, was calculated (subsequently referred to as revision for any reason). The third, worst-case scenario analysis looked at revision for any reason as the endpoint, with any lost to follow-up patients treated as revisions

In the first and second scenarios, the survival analyses were computed treating any patient lost to follow-up as 
a death. It has been recognised that the presence of death competing as a censoring event can result in incomplete accounting of the likelihood of revision [11]. To address this concern we have also calculated the rates of revision as the number of revisions per 100 observed component years as reported elsewhere [12].

\section{Results}

The mean follow-up at the time of the review was 8.5 years ( 0 to 19) at which time 87 of the 228 knees where withdrawn due to death of patients, all of whom died from unrelated causes. The mean elapsed time for these knees from implantation to death was 7.2 years ( 0.5 to 17). A total of ten knees involving seven patients had been lost to follow-up at a mean of 7.8 years ( 3 to 13; for knees), of whom four patients (six knees) had emigrated. In all, 19 knees (19 patients) underwent revision for any reason: ten knees were revised for aseptic loosening at a mean of 7.3 years (1 to 12) years and six knees were revised due to peri-prosthetic infection at a mean of 2.1 years ( 0.5 to 4 ), two knees underwent revision in the course of the management of a periprosthetic fracture at one week and eight years respectively, and one knee was revised elsewhere for pain at one year post-operatively. This patient had completed extensive investigation with serological investigation, serial radiography, radio-isotopic scanning, aspiration and culture, and arthroscopy, biopsy and culture. None of the investigations had identified loosening or infection. Nevertheless, following a second opinion revision was performed which confirmed the absence of infection or loosening. Following revision he continued to experience pain, which was subsequently attributed to a neurological cause. This patient was included in the analysis as revised but not loose, along with the implants revised for periprosthetic infection and fracture. No patients were found to be pending revision or to have a failed implant for which revision was precluded.

For aseptic loosening as the censor point, at ten years the survival rate was 96.7\% (95\% CI: 93.3 - 100) when 125 prostheses were at risk and at 14 years $91.5 \%$ (95\% CI: 82.1 - 100) when 38 prostheses were at risk (Table 1).

For revision for any reason, at ten years the survival rate was 92.3\% (95\% CI: 87.7 - 97.3) when 125 prostheses were at risk, and at 14 years $87.1 \%$ (95\% CI: 76.4 - 99.2) when 38 prostheses were at risk (Table 2). The

Table 1. Life-table analysis with revision for aseptic loosing as the censor point.

\begin{tabular}{|c|c|c|c|c|c|c|c|c|}
\hline $\begin{array}{l}\text { Years since } \\
\text { operation }\end{array}$ & $\begin{array}{c}\text { Start } \\
\text { number }\end{array}$ & $\begin{array}{c}\text { Fail } \\
\text { number }\end{array}$ & Died & Lost & $\begin{array}{l}\text { Revised but } \\
\text { not loose }\end{array}$ & $\begin{array}{l}\text { Number at risk at } \\
\text { end of period }\end{array}$ & $\begin{array}{l}\text { Survival } \\
\text { rate } \%\end{array}$ & $95 \%$ CI \\
\hline 0 to 1 & 228 & 2 & 5 & 0 & 4 & 223.5 & 99.1 & 100 to 100 \\
\hline 1 to 2 & 217 & 0 & 8 & 0 & 2 & 212 & 99.1 & 99.1 to 99.1 \\
\hline 2 to 3 & 207 & 0 & 5 & 2 & 1 & 203 & 99.1 & 99.1 to 99.1 \\
\hline 3 to 4 & 199 & 0 & 7 & 0 & 0 & 195.5 & 99.1 & 99.1 to 99.1 \\
\hline 4 to 5 & 192 & 2 & 5 & 1 & 1 & 188.5 & 98 & 99.1 to 99.1 \\
\hline 5 to 6 & 183 & 0 & 8 & 0 & 0 & 179 & 98 & 96.1 to 99.9 \\
\hline 6 to 7 & 175 & 0 & 9 & 3 & 0 & 169 & 98 & 96.1 to 99.9 \\
\hline 7 to 8 & 163 & 1 & 14 & 1 & 1 & 155 & 97.4 & 96.1 to 99.9 \\
\hline 8 to 9 & 146 & 1 & 6 & 0 & 0 & 136 & 96.7 & 94.7 to 100 \\
\hline 9 to 10 & 125 & 0 & 3 & 0 & 0 & 113.5 & 96.7 & 93.5 to 100 \\
\hline 10 to 11 & 102 & 3 & 5 & 0 & 0 & 85.5 & 93.2 & 92.9 to 100 \\
\hline 11 to 12 & 66 & 1 & 2 & 2 & 0 & 59 & 91.5 & 87.3 to 99.4 \\
\hline 12 to 13 & 51 & 0 & 1 & 1 & 0 & 44.5 & 91.5 & 83.9 to 99.6 \\
\hline 13 to 14 & 38 & 0 & 3 & 0 & 0 & 28 & 91.5 & 82.1 to 100 \\
\hline 14 to 15 & 18 & 0 & 4 & 0 & 0 & 13.5 & 91.5 & 77.7 to 100 \\
\hline 15 to 16 & 9 & 0 & 1 & 0 & 0 & 7.5 & 91.5 & 72.9 to 100 \\
\hline 16 to 17 & 6 & 0 & 1 & 0 & 0 & 5 & 91.5 & 68.7 to 100 \\
\hline 17 to 18 & 4 & 0 & 0 & 0 & 0 & 3.5 & 91.5 & 64.2 to 100 \\
\hline 18 to 19 & 3 & 0 & 0 & 0 & 0 & 1.5 & 91.5 & 49.6 to 100 \\
\hline
\end{tabular}


Table 2. Life-table analysis with revision for any reason as the censor point.

\begin{tabular}{|c|c|c|c|c|c|c|c|}
\hline $\begin{array}{l}\text { Years since } \\
\text { operation }\end{array}$ & $\begin{array}{c}\text { Start } \\
\text { number }\end{array}$ & $\begin{array}{c}\text { Fail } \\
\text { number }\end{array}$ & Died & Lost & $\begin{array}{c}\text { Number at risk at end } \\
\text { of period }\end{array}$ & $\begin{array}{l}\text { Survival } \\
\text { rate } \%\end{array}$ & $95 \% \mathrm{CI}$ \\
\hline 0 to 1 & 228 & 6 & 5 & 0 & 222.5 & 97.3 & 100 to 100 \\
\hline 1 to 2 & 217 & 2 & 8 & 0 & 213 & 96.4 & 95.4 to 99.2 \\
\hline 2 to 3 & 207 & 1 & 5 & 2 & 203.5 & 95.9 & 93.7 to 99.1 \\
\hline 3 to 4 & 199 & 0 & 7 & 0 & 195.5 & 95.9 & 93.3 to 98.6 \\
\hline 4 to 5 & 192 & 3 & 5 & 1 & 189 & 94.3 & 93.3 to 98.6 \\
\hline 5 to 6 & 183 & 0 & 8 & 0 & 179 & 94.3 & 91.2 to 97.6 \\
\hline 6 to 7 & 175 & 0 & 9 & 3 & 169 & 94.3 & 91.2 to 97.6 \\
\hline 7 to 8 & 163 & 2 & 14 & 1 & 155.5 & 93 & 90.7 to 98.1 \\
\hline 8 to 9 & 146 & 1 & 6 & 0 & 136 & 92.3 & 89.1 to 97.3 \\
\hline 9 to 10 & 125 & 0 & 3 & 0 & 113.5 & 92.3 & 87.7 to 97.3 \\
\hline 10 to 11 & 102 & 3 & 5 & 0 & 85.5 & 88.8 & 87.1 to 98.0 \\
\hline 11 to 12 & 66 & 1 & 2 & 2 & 59 & 87.1 & 81.9 to 96.7 \\
\hline 12 to 13 & 51 & 0 & 1 & 1 & 44.5 & 87.1 & 78.7 to 96.9 \\
\hline 13 to 14 & 38 & 0 & 3 & 0 & 28 & 87.1 & 76.4 to 99.2 \\
\hline 14 to 15 & 18 & 0 & 4 & 0 & 13.5 & 87.1 & 71.4 to 100 \\
\hline 15 to 16 & 9 & 0 & 1 & 0 & 7.5 & 87.1 & 65.8 to 100 \\
\hline 16 to 17 & 6 & 0 & 1 & 0 & 5 & 87.1 & 60.8 to 100 \\
\hline 17 to 18 & 4 & 0 & 0 & 0 & 3.5 & 87.1 & 55.6 to 100 \\
\hline 18 to 19 & 3 & 0 & 0 & 0 & 1.5 & 87.1 & 38.6 to 100 \\
\hline
\end{tabular}

worst-case scenario with lost knees also treated as revisions reduced the ten-year survival rate to $88.5 \%$ (95\% CI: 83.8 - 94.3) and at 14 years to 78.1\% (95\% CI: 67.9 - 92.2). The revision rate for aseptic loosening per 100 observed component-years was $0.513 \%(95 \% \mathrm{CI}$ : $-0.007-1.055)$. The equivalent analysis for revision for any reason was 0.974 (95\% CI: 0.465 - 1.527).

\section{Discussion}

Our extended survival analysis has revealed that at ten years, with 125 prostheses at risk, for revision for aseptic loosening and revision for any reason, there has been a small deterioration in the survivorship from our original report when only 25 knees are at risk [1]. The nearest comparison possible from NJR data related to the 2014 Annual Report which identified a ten-year all cause revision rate for the Medial Rotation TKA of 2.96\% (95\% CI: 2.07 - 4.21) using the Kaplan-Meier method for its calculation [13]. That figure appears better than our survival rate at ten years with revision for any reason of 92.3\% (95\% CI: 87.7 - 97.3). It will be acknowledged that since its inception in 2003, the NJR has not published an audit of the accuracy of the data it collates. An independent analysis of revision data for metal-on-metal hip replacements has found incomplete registration of revisions with the NJR [14]. We have undertaken a detailed review of our original cohort and are only unable to account for the outcome of seven patients (ten knees), of whom four patients (six knees) have emigrated. The mean time for this loss to follow-up is 7.8 years (3 to 13; for knees). We believe our analysis to be more dependable than that of the NJR and provide a better estimate of prosthetic survivorship, since all deaths and revisions have been identified with the exception of those lost to follow-up who will not even be noticed by the NJR.

We accept that this study has limitations: we have not provided any radiological analysis or long-term clinical outcome results. Accordingly, we may not have identified patients with failing prostheses, but comment that the NJR does undertake such detailed analyses either. We are aware that a surviving reconstruction is not syn- 
onymous with complete satisfaction in the outcome [15]. Notwithstanding, as we trace our patients anyone who has concerns about their TKA being invited to seek referral from their GP. This results in only two consultations, one of which relates to arthritis in the ipse-lateral hip and one for pain in the contralateral knee. No patient is referred for re-evaluation of the existing TKA.

Neither the 11th Annual Report of the NJR [13], nor the Australian Orthopaedic Association National Joint Replacement Registry [16], uses the methodology of the revision rate per 100 observed component-years. This system has been used by the New Zealand Joint Registry (NZJR) and in their 14 year report and has identified an overall revision rate revision rate per 100 observed component-years for 64,556 primary TKAs to be $0.50 \%$ (95\% CI: 0.48 - 0.52), but has no specified information for the Medial Rotation TKA [17]. For our cohort of 228 TKAs in the comparable analysis for revision for any reason is greater at $0.974 \%$ (95\% CI: 0.465 - 1.527 ). However, our cohort is trivially small compared with the overall number of TKAs studied by the NZJR, and our CIs are necessarily much wider preventing any inference from being made.

In conclusion, our follow-up analysis with a more appropriate number of prostheses at risk (125 TKAs) at ten years shows the Medial Rotation TKA, by the life-table method, to have a survival rate is 92.3\% (95\% CI: 87.7 97.3), with revision for any cause as the endpoint. This figure represents a deterioration in survivorship for the prosthesis at ten years compared to our initial report, when it is 94.5\% (95\% CI: 85.1 - 100) when only 21 prostheses were at risk. Results of our updated report serve to underline the importance of scrutinizing one's own results, which necessarily deteriorate as time goes on, with careful interrogation of a prospectively collated database for deaths and revisions. The varying methodologies adopted by national joint registries make comparisons difficult. Nevertheless, compared to the NJR ten-year Kaplan-Meier estimated cumulative probability of first revision of 2.96\% (95\% CI: 2.07 - 4.21) [13], our outcome looks less favourable. The reasons for this may be manifold; not least it may reflect uncertainties in the inclusion of complete information in national registries, which is a problem likely to affect the data for all designs of prosthesis.

\section{References}

[1] Mannan, K. and Scott, G. (2009) The Medial Rotation Total Knee Replacement. A Clinical and Radiological Review at a Mean Follow-Up of Six Years. The Journal of Bone \& Joint Surgery, 91-B, 750-756. http://dx.doi.org/10.1302/0301-620X.91B6.22124

[2] (2012) 9th Annual Report National Joint Registry for England and Wales. NJR Centre, Northgate Solutions, Hemel Hempstead.

[3] (2013)10th Annual Report National Joint Registry for England, Wales and Northern Ireland. NJR Centre, Northgate Solutions, Hemel Hempstead.

[4] Blaha, J.D. (2004) The Rationale for a Total Knee Implant That Confers Anteroposterior Stability throughout the Range of Motion. The Journal of Arthroplasty, 19, 22-26. http://dx.doi.org/10.1016/j.arth.2004.04.002

[5] Iwaki, H., Pinskerova, V. and Freeman, M.A.R. (2000) Tibiofemoral Movement 1: The Shapes and Relative Movements of the Femur and Tibia in the Unloaded Cadaver Knee. The Journal of Bone \& Joint Surgery, 82-B, 1189-1195. http://dx.doi.org/10.1302/0301-620X.82B8.10717

[6] Hill, P.F., Vedi, V., Williams, A., Iwaki, H., Pinskerova, V.and Freeman, M.A.R. (2000) Tibiofemoral Movement 2: The Loaded and Unloaded Living Knee Studied by MRI. The Journal of Bone \& Joint Surgery, 82-B, 1196-1198. http://dx.doi.org/10.1302/0301-620X.82B8.10716

[7] Pinskerova, V., Johal, P., Nakagawa, S., et al. (2004) Does the Femur Roll-Back with Flexion? The Journal of Bone \& Joint Surgery, 86-B, 925-931. http://dx.doi.org/10.1302/0301-620X.86B6.14589

[8] Pinskerova, V., Samuelson, K.M., Stammers, J., Maruthainar, K., Sosna, A. and Freeman, M.A.R. (2009) The Knee in Full Flexion: An Anatomical Study. The Journal of Bone \& Joint Surgery, 91-B, 830-834. http://dx.doi.org/10.1302/0301-620X.91B6.22319

[9] Armitage, P. and Berry, G. (1994) Statistical Methods in Medical Research. 3rd Edition, Blackwell Scientific Publications, Oxford.

[10] Murray, D.W., Carr, A.J. and Bulstrode, C. (1993) Survival Analysis of Joint Replacements. The Journal of Bone \& Joint Surgery, 75-B, 697-704.

[11] Fennema, P. and Lubsen, J. (2010) Survival Analysis in Total Joint Replacement. An Alternative Method of Accounting for the Presence of Competing Risk. The Journal of Bone \& Joint Surgery, 92-B, 701-706. http://dx.doi.org/10.1302/0301-620X.92B5.23470

[12] Hooper, G.J., Rothwell, A.G., Stringer, M. and Frampton, C. (2009) Revision Following Cemented and Uncemented 
Primary Total Hip Replacement. A Seven-Year Analysis from the New Zealand Joint Registry. The Journal of Bone \& Joint Surgery, 91-B, 451-458. http://dx.doi.org/10.1302/0301-620X.91B4.21363

[13] (2014) 11th Annual Report National Joint Registry for England, Wales and Northern Ireland. NJR Centre, Northgate Solutions, Hemel Hempstead.

[14] Sabah, S.A., Henckel, J., Cook, E., et al. (2015) Validation of Primary Metal-On Metal Hip Arthroplasties on the National Joint Registry for England, Wales and Northern Ireland Using Data From The London Implant Retrieval Centre: A Study Using the NJR Dataset. The Bone \& Joint Journal, 97-B, 10-18. http://dx.doi.org/10.1302/0301-620X.97B1.35279

[15] Nam, D., Nunley, R.M. and Barrack, R.L. (2014) Patient Dissatisfaction Following Total Knee Replacement. A Growing Concern. The Bone \& Joint Journal, 96-B, 96-100. http://dx.doi.org/10.1302/0301-620X.96B11.34152

[16] (2014) Australian Orthopaedic Association National Joint Replacement Registry Annual Report. https://aoanjrr.dmac.adelaide.edu.au/documents/10180/172286/Annual\%20Report\%202014

[17] (2013) The New Zealand Joint Registry 14 Year Report. www.nzoa.org.nz/system/files/NJR\%2014\%20Year\%20Report.pdf 